\title{
La muerte simbólica y material de la ciudad: una aproximación sobre el urbanicidio
}

\author{
Víctor Delgadillo Polanco
}

Artículo

Afiliación: Universidad Autónoma de la Ciudad de México, Ciudad de México, Mexico.

E-mail: victor_delgadill@hotmail.com

Recibido: 25 de junio del 2020

Aceptado: 29 de octubre del 2020

\section{Víctor Delgadillo Polanco}

Doctor en urbanismo (Universidad Nacional Autónoma de México), Maestro en planificación urbana (Universidad de Stuttgart) y Arquitecto (Universidad Autónoma de Puebla). Investigador Nacional Nivel Dos (SNI CONACYT). Ha publicado seis libros y alrededor de cien artículos en revistas y libros en diversos países. Profesor investigador del Colegio de Humanidades y Ciencias Sociales de la Universidad Autónoma de la Ciudad de México.

\begin{abstract}
Resumen:
Las imágenes de ciudades sin gente que recientemente hemos visto en muchas partes del mundo debido a la pandemia provocada por el COVID-19 no muestran algo totalmente nuevo, pues la muerte simbólica y material de la ciudad acecha desde hace tiempo. El presente artículo investiga, a partir de los aportes de diversos autores, ciencias y disciplinas sociales, sobre la muerte real y virtual de la ciudad, así como sobre la pérdida de los atributos que la definen como tal. Algunas de estas cualidades son: la concentración y diversidad de espacios que permiten el encuentro y las relaciones de vecindad; la proximidad, el convivio, la solidaridad y el conflicto entre personas y agentes diversos; la mezcla social y económica; la diversidad cultural; la mixtura de actividades (trabajar, consumir, residir) y usos del suelo; y la comunidad política de ciudadanos que gobiernan y deciden sobre los asuntos públicos. Este escrito revisa las diversas causas sociales, económicas y políticas que, con la consolidación del neoliberalismo como doctrina y sistema económico, han erosionado la ciudad como concepto, modo y lugar de la vida social.
\end{abstract}

Palabras clave: Despilfarro urbano, destrucción creativa, obsolescencia programada, urbanicidio.

The symbolic and material death of the city: an approach about the urbicide

\begin{abstract}
:
The images of cities without people, which we recent haven seen in many parts of the world, because of the COVID 19 Pandemic, do not show us anything totally new, as the symbolic and material death of the city threat us since long time ago. This article explores, from the contributions of diverse authors, sciences and social disciplines, on the real and virtual death of the city, as well as on the loss of attributes that define the city as such: the concentration and diversity of places that permit social meetings and the neighborhood relations; the proximity, coexistence, solidarity and conflict between diverse peoples and agents; the social and economic mix; the cultural diversity; the mix of activities and land uses; as well as the political community of citizens who govern and decide on public affairs. The article reviews the various social, economic and political causes that, with the consolidation of the neoliberalism as doctrine as well as economic system, have eroded the city as a concept, way and place of life.
\end{abstract}

Keywords: Urban waste, creative destruction, programmed obsolescence, urbicide. 


\section{Introducción}

$\mathrm{n}$ los últimos meses se han visto imágenes extrañas y perturbadoras de ciudades sin gente en muchas partes del mundo, en varias de ellas aparecieron animales silvestres deambulando en calles vacías, como si fueran escenas de una película surrealista de Buñuel (El Ángel Exterminador); imágenes provenientes de la ciencia ficción; o postales hechas para ilustrar el libro de Spengler sobre el declive de la civilización occidental. Estas imágenes motivaron este ensayo que examina la muerte material y simbólica de la ciudad, es decir, la destrucción física de la ciudad y la pérdida de los atributos que la definen como tal.

Las ciudades son artefactos producidos por generaciones de personas que se utilizan para vivir colectivamente. Expresan que los humanos tienen como vocación natural vivir reunidos y relacionarse unos con otros. Los seres humanos son sujetos sociales que por gusto, herencia y necesidad habitan colectivamente, es decir, los humanos somos seres gregarios. En este sentido, las ciudades han sido entendidas como la cúspide del proceso civilizatorio, la máxima creación humana para vivir mejor y los sitios en donde han emergido y se han conquistado los derechos humanos (políticos, económicos y sociales). Así, la ciudad fue pensada para que los humanos viviéramos juntos y fue construida para durar en el tiempo. Por supuesto que también las ciudades históricamente han sido sitios de exclusión, control social y político, zonas de privilegiados y territorios de desigualdades múltiples, pues la historia de la humanidad ha sido la historia de las desigualdades sociales en el marco de relaciones asimétricas de poder. Además, estas disparidades se han polarizado en la fase actual del capitalismo neoliberal globalizado. Así, el concepto de ciudad que reivindicamos es más una aspiración que una realidad. En este ensayo revisamos el origen del concepto urbanicidio y las causas de la destrucción material, total o parcial, de la ciudad'. Enseguida analizamos la muerte simbólica de la ciudad, es decir, la pérdida de los atributos de la ciudad. A manera de colofón, sostenemos que indagar sobre la muerte de la ciudad no se deriva del culto a las ruinas, sino de una idea que sostiene que si entendemos las causas que conducen a la destrucción física y a la erosión de sus atributos, estaremos en mejores condiciones de defender y proteger la ciudad, nuestra herencia colectiva, en beneficio de la gente.

\section{Urbanicidio}

Este vocablo proviene del latín urbs, urbe, y cidio, acción de matar. Es menos usual el concepto urbicidio que corresponde a la traducción del anglicismo urbicide para referirse al mismo significado. Urbe se usa en Iberoamérica como sinónimo de ciudad (civitas), especialmente una muy populosa, gran ciudad o metrópolis (Topalov, Coudroy y Depaule, 2010). En términos materiales, la ciudad se extermina a través de destrucciones intencionales o "naturales" que impactan diversas condiciones de vulnerabilidad socialmente construidas. En términos simbólicos, las estructuras físicas se mantienen, pero se aniquilan los atributos que definen la ciudad: la mezcla social y económica; la diversidad cultural; la mixtura de actividades (residir, trabajar, consumir, recrear, etcétera) y usos del suelo; la comunidad política que se autogobierna y decide sobre lo público; y las relaciones de vecindad, proximidad, convivio, solidaridad y

$1 \quad$ No hay espacio para abordar la reconstrucción de la ciudad y problematizar sobre clones urbanos, copias "originales", facsímiles arquitectónicos, simulacros y falsos históricos; 0 para discutir la cultura de la reconstrucción urbana, presente en regiones que cíclicamente sufren desastres, como la consignada provocadoramente por la Fondazioni Triennale di Milano (2018). conflicto entre actores y agentes diversos.

Settis (2019) añade que las ciudades también mueren cuando sus habitantes pierden su memoria colectiva y se convierten en extraños en su propia ciudad. En períodos caracterizados por conflictos armados y revueltas el urbanicidio se asocia a la destrucción física de la ciudad. Mientras que en tiempos de paz son causas sociales, políticas y económicas, las que conducen al aniquilamiento de los atributos de la ciudad, entendida como urbs, civitas y polis. Para Carrión (2018a) el concepto urbicidio nació en la década de 1960 y se usó para referirse a la destrucción física de las ciudades provocada por las guerras y la renovación urbana que expulsó a gente pobre de la ciudad y sus barrios. 
Curiosamente, en la década de 1970, con la emergencia de la consciencia ecologista, el concepto urbanicidio se usó en Argentina y Chile para referirse a la mala calidad de vida en las ciudades. La muerte de la ciudad ocurría por contaminación, ruido, tráfico y congestión urbana (Memoria Chilena, 2020).

\section{La muerte física de la ciudad}

Las causas de la destrucción de las ciudades son naturales y sociales (Lynch, 2005; Körner, 1999 y 2000). Entre las primeras se ubican inundaciones, huracanes, tornados, ciclones, sismos, erupciones volcánicas, tsunamis, incendios, entre otros. Varios de estos fenómenos naturales han sido intensificados, en su dimensión y periodicidad, por el cambio climático, que a su vez ha sido originado por la depredación capitalista de la naturaleza. Los fenómenos naturales actúan en entornos socialmente construidos con diversas condiciones de vulnerabilidad. Así, si una ciudad está bien construida, tanto por los materiales y sistemas constructivos, como por los sitios donde se emplaza, no tendría por qué ser devastada ( 0 al menos en menor medida) por un evento natural. El fenómeno natural no se puede impedir, pero se puede prever con determinadas medidas, a su vez, la población puede disminuir su impacto para evitar que ese fenómeno natural produzca un desastre social ${ }^{2}$.

Entre las causas sociales destacan las guerras y revoluciones, pero también procesos de modernización y embellecimiento urbano, que a menudo son expresiones de ideologías dominantes y/o de negocios inmobiliarios. Wikipedia (2020) tiene -en inglésuna entrada del concepto Urbicide, que se refiere a la destrucción de las ciudades por guerras para destruir al enemigo, socavar las bases materiales de la vida de sus habitantes, expulsar a la gente y destruir la memoria e identidad colectiva. Wikipedia (2020) cita dos acepciones de origen latino: una, dice que Urbicide viene de urbs (ciudad) y caedere (asesinar o cortar); y otra que dice que proviene de urbs y occido (masacre).

La destrucción de las ciudades por guerras es muy antigua (Jouannais, 2017) y muy reciente: podrían mencionarse como ejemplos Bagdad, Beirut, Dresde, Guernica, Hiroshima, México Tenochtitlán, Palmira, Roma y Sarajevo. A menudo el aniquilamiento se concentra en determinados edificios y lugares, no porque sean estratégicos en términos militares, sino por la carga simbólica, socialmente construida, asociada a los edificios y lugares. Bevan (2006) sostiene que en las guerras se libran otros conflictos como la destrucción de los artefactos culturales de los enemigos con el propósito de dominar, aterrorizar, dividir o erradicar los símbolos culturales de los otros. Aquí, el patrimonio edificado toma una dimensión totémica y deja de ser lo que simplemente es para constituirse en un símbolo marcado para ser destruido, porque corporiza la presencia del enemigo. De ninguna manera se trata de daños colaterales, sino de una activa y sistemática destrucción de cierto tipo de edificios y de arquitectura tradicional, que se hace para aniquilar el pasado y el futuro, la memoria, la historia y la identidad adjudicada simbólicamente a determinada arquitectura.

Hay muchísimos ejemplos de este tipo de fenómeno: durante la II Guerra Mundial los nazis destruyeron sistemáticamente, edificio por edificio, la ciudad de Varsovia ${ }^{3}$. Guernica fue masacrada por los aliados de Franco. En la Blitzkrieg, los monumentos de las ciudades inglesas se convirtieron en objetivos "tres estrellas" para la aviación alemana, mientras los ingleses atacaron las ciudades históricas alemanas. Casi al finalizar este conflicto bélico, los aliados arrasaron con las ciudades alemanas de una forma tan o más cruel que la practicada por los nazis. Sebald (2003), quien sostiene que los alemanes por su complejo de culpa no se atreven a hablar de esto, construyó sobre estos hechos su Historia Natural de la Destrucción.

Entre los casos más recientes destaca la guerra de los Balcanes, donde el patrimonio urbano de Bosnia Herzegovina y Croacia fue un blanco específico del conflicto, pues perecieron mezquitas, templos, bibliotecas y otras construcciones icónicas. Coward (2009) sostiene que en los Balcanes explícitamente se pretendió aniquilar la diversidad sociocultural y la heterogeneidad étnica de esas ciudades. Así, la ciudad, sinónimo de multiculturalidad, respeto y tolerancia entre los diversos, fue objeto de limpieza étnica. 
Los cambios de régimen también conducen a la destrucción parcial de la ciudad. Durante la Revolución Francesa se demolieron monumentos y edificios de la aristocracia, los insurrectos se vengaban con los símbolos de la opresión del régimen derrocado que constituían un insulto a la pobreza y a la moral de la Revolución. En este sentido, el vandalismo revolucionario tiene razones políticas, no es un acto de barbarie (Gamboni, 2014). El régimen de Stalin atacó la arquitectura religiosa y vestigios de la Rusia zarista. Mussolini destruyó vestigios romanos y medievales para engrandecer con nuevas avenidas la Roma fascista. Mientras en Berlín, después de ser designada como capital de la Alemania reunificada, se destruyó el pasado socialista a nombre de la fealdad de la arquitectura y de que los edificios estaban construidos con asbesto, para reconstruir un castillo barroco destruido por motivos ideológicos hacia 1957 bajo el gobierno de la República Democrática Alemana. En este mismo sentido, en las ciudades ex socialistas de Europa del Este, se han derrumbado los monumentos conmemorativos y las estatuas de los héroes o villanos comunistas, con la caída del socialismo real. Asimismo, en pleno 2020, en los Estados Unidos asistimos al derrumbe de estatuas conmemorativas de personajes de la historia asociados al esclavismo, este vandalismo fue desencadenado por el asesinato de un ciudadano afroamericano a manos de la policía.

Por su parte, las causas económicas que conducen a la destrucción directa e indirecta de la ciudad o sus partes, pueden actuar en periodos más largos y de manera progresiva. En efecto, el urbanicidio, en su dimensión física, muy frecuentemente se comete por especulación, modernización y renovación urbana, es decir, por lucro. Deshacerse de lugares que aún son útiles constituye un despilfarro urbano, es la lógica capitalista de la destrucción creativa. La destrucción de edificios, barrios y ciudades a menudo se legitima en el deterioro, la decadencia y el agotamiento de lo construido con sus diferentes velocidades y múltiples causas (mantenimiento, hábitos, condiciones de habitabilidad, entre otros); así como en el discurso de los ciclos naturales de vida. Para Jacobs (1967) el deterioro no tenía nada de natural y sí mucho de especulación inmobiliaria.

El urbanicidio progresivo suele comenzar con la sustitución de edificios de bajas alturas por nuevos edificios de más pisos que capturan mayores rentas, pero al hacer esto, también se arrasan barrios y ciudades enteras. En Echar a perder, Lynch (2005) denuncia el despilfarro que constituye la lógica capitalista de estar haciendo todo nuevo: electrodomésticos, automóviles, edificios, barrios, ciudades. Byles (2005) ejemplifica esto con las grandes autopistas que Robert Moses construyó en Nueva York y destruyeron barrios y desplazaron 250,000 personas en nombre del progreso. En esa ciudad, Berman (1993), oriundo del Bronx, ejemplifica la tragedia de la modernidad en la construcción de la carretera Cross Bronx que dividió su barrio y brutalmente destruyó las formas de vida locales.

Por su parte, el tránsito de la industrialización fordista a una postfordista, caracterizada por la fragmentación de los procesos productivos y su dispersión geográfica en países con mano de obra barata, llevaron a la desindustrialización y declive económico de muchas ciudades del mundo. Un ejemplo, tal vez el peor, es Detroit, epicentro del moderno urbanicidio: de los dos millones de habitantes que tuvo esa ciudad, en 2005 quedaban menos 700 mil residentes y ya había 78,000 viviendas deshabitadas (Byles, 2005).

Las estrategias y mecanismos de la destrucción creativa son muy diversos, abarcan la destrucción de bienes consumibles con diversos métodos (incluyendo el uso de dinamita), la creación de nuevas necesidades y la programación de una obsolescencia artificial de los bienes materiales, a través de la construcción de modas de consumo y del empleo de materiales perecibles a corto plazo. Esta también es la lógica de la renovación urbana y del mercado inmobiliario. Un claro ejemplo lo constituyen los conjuntos de viviendas sociales de dimensiones y calidad miserables construidas en periferias urbanas distantes en México, Chile y Brasil. Esas urbanizaciones se edifican en suelo barato lejano de las ciudades, empleos y equipamientos colectivos. Además, las viviendas son de tan mala calidad, que cuando los hogares terminen de pagarlas, necesitarán nuevos financiamientos para reconstruirlas. Esto no es algo exclusivo de la vivienda social, muchas nuevas construcciones ya no sobreviven sino sólo una 
generación humana y muchos megaproyectos inmobiliarios se transforman rápidamente en ruinas (Agulles, 2017; Consejo Nocturno, 2018).

Por último, entre las causas económicas que matan a la ciudad está el turismo, que transforma ciudades y centros históricos en museos a cielo abierto y en parques temáticos para el consumo homogeneizado de visitantes ávidos de lugares "auténticos" (Augé, 2008). Venecia es el mejor ejemplo de una ciudad que atrae a millones de turistas, a costa de desplazar a sus residentes. Settis (2019) denuncia que una serie de nuevos megaproyectos (Aqualta 2060, Torre Cardin, Veneto Green City, entre otros) sumados al turismo de masas, están conduciendo al suicidio ${ }^{4}$ de Venecia.

No es un caso aislado, muchas ciudades y centros históricos se quedan paulatinamente sin residentes y se convierten en cascarones ultra securitizados, deshabitados y destinados al consumo de visitantes (Consejo Nocturno, 2018). Bonnet (2016), por ejemplo, denuncia la demolición del $95 \%$ de La Meca para transformar esa ciudad al servicio de tres millones de peregrinos anuales: allí se purga el pasado para alojar a las grandes marcas comerciales del presente. En este mismo sentido, Brossat (2019), responsable de la vivienda en París entre 2014 y 2018, denuncia la canibalización de los barrios producida por AirBnB: esa plataforma digital lucra con viviendas y barrios que no son suyos, incrementa las rentas, expulsa a los residentes y sustituye los comercios y servicios de proximidad por otros al servicio de los visitantes. Además, evade el pago de impuestos registrando sus actividades en paraísos fiscales.

\section{La muerte de los atributos de la ciudad}

La ciudad es un concepto y realidad multidimensional que hunde sus raíces en el occidente grecolatino y remite a un espacio construido por generaciones de personas para vivir bien y colectivamente (Chueca Goitia, 1977; Park, 1999). La ciudad es un espacio físico de uso colectivo (urbs en latín), una comunidad de ciudadanos con derechos y obligaciones sobre lo público (civitas en latín) y una comunidad política que se autogobierna (polis en griego) (Borja, 2003; Capel, 2003; Carrión, 2008; Choay, 2009; Delgadillo, 2016). Así, la ciudad es parte del proceso civilizatorio y de conquista de las libertades y los derechos humanos.

Una ciudad es, asimismo, una alta densidad de sujetos diversos y heterogéneos (en términos socioeconómicos, culturales, etcétera) con intereses diferentes que de manera cohesionada (con)viven y coexisten en un espacio físico limitado (Wirth, 1988), gracias a la tolerancia y respeto al pacto social (Simmel, citado en Remy, 2012). Por ello, la ciudad, nuestro patrimonio, ha sido definida como un espacio público por excelencia, de interés común y general para la población que en ella habita o que la visita (Borja, 2011; Carrión, 2008). La ciudad no es el territorio, sino los lazos y las relaciones sociales que en ella se construyen (Agulles, 2017).

Una ciudad no es un escenario en el que ocurren los procesos sociales y se disputa el poder, tampoco es un espacio preexistente neutro y despolitizado. La ciudad es un producto histórico, social y político, es el lugar de la reproducción de las relaciones sociales de producción. Es un espacio socialmente disputado en condiciones desiguales de poder, por diversos actores y agentes sociales, políticos y económicos que se apropian de ese espacio para usarlo, habitarlo, explotarlo, dominarlo y/o controlarlo (Lefebvre, 2013). Así, históricamente la ciudad ha sido un espacio en el que los conflictos se resuelven en el marco de un orden establecido y de relaciones asimétricas de poder.

4. Settis (2019) usa el término suicidio, porque -según él- son las propias autoridades y los habitantes omisos, quienes con sus acciones conducen a la muerte de Venecia.
En 2020, la mayor parte de la población del mundo vive en ciudades que más que "ciudades" como tal son urbanizaciones. Los nuevos asentamientos humanos que se han construido recientemente en periferias cada vez más lejanas son áreas dormitorio homogéneas; los centros históricos se despueblan, turistifican, parquetematizan y se tornan exclusivos para consumidores de mayores ingresos; mientras que las telecomunicaciones han transformado las relaciones que las sociedades mantenían con su espacio y tiempo. El COVID-19 ha intensificado el trabajo en casa, la educación a distancia, el consumo de tecnologías de comunicación e información, y ha fortalecido el capitalismo de plataformas digitales de entretenimiento y servicio de entregas a domicilio. 
En este sentido, parecen tan actuales las reflexiones de Choay (2009): la interacción entre las personas se ha desterritorializado, la pertenencia a las comunidades ya no se funda en la proximidad territorial y las ciudades ya no alojan la mezcla y diversidad social.

En este mismo sentido, Bookchin (1974) y Mongin (2006) defienden la idea de una ciudad que respondía a la cultura de los límites, una ciudad que integraba y relacionaba a los diferentes, favorecía la mezcla social, la confluencia y el encuentro; mientras que la intrínseca conflictividad social estaba mediada por la urbanidad y la tolerancia. Sin embargo, desde hace décadas esa ciudad, símbolo de la emancipación y la integración social, se confronta con una dinámica metropolitana y una globalización que dividen, dispersan, fragmentan, privatizan, descentralizan, separan y crean nuevas y diversas jerarquías urbanas y territoriales. En este sentido, la ciudad ya no reúne, integra y relaciona.

En las últimas décadas asistimos a procesos de expansión urbana en diversas regiones del mundo. Se trata de una urbanización planetaria que, según Agulles (2017), dinamita la noción de límites, sepulta y niega la ciudad como forma histórica y social de habitar el espacio. Así, ya no hay "ciudad" sino una capa urbana planetaria dispersa, sin forma ni orden, ilimitada e indefinida en un continuum mundial (Consejo Nocturno, 2018). Carrión (2018b) añade la violencia y delincuencia urbana como causas del urbanicidio en América Latina, pues provoca el miedo al espacio público, el autoconfinamiento de grupos sociales en asentamientos cerrados, el cierre de calles, y legitimación de diversas políticas punitivas de seguridad pública. Curiosamente, durante el confinamiento COVID 19 los delitos en la vía pública y los robos a viviendas han disminuido, pero la violencia intrafamiliar se ha incrementado, particularmente contra las mujeres.

Desde una perspectiva económica (Carrión, 2018a; Delgadillo, 2016), los nuevos negocios inmobiliarios contribuyen a matar los atributos de la ciudad porque producen islas urbanas exclusivas y excluyentes, y terminan por encarecer selectos barrios y desplazar directa e indirectamente a la población que allí residía, produciendo procesos de gentrificación y profundizando la histórica segregación urbana. Para Borja (2011) este urbanicidio es un urbanismo del miedo a la ciudad, la diversidad y la mezcla socioeconómica, es un urbanismo de fragmentos aislados que responde a la lógica de lucrativos negocios privados, y suele acompañarse de códigos de buen comportamiento en el espacio público, que expulsan a los vendedores informales y la población en situación de calle. En síntesis, este urbanismo neoliberal erosiona la vida colectiva y política, coloca la gestión urbana al servicio del lucro, mercantiliza la ciudad y sus partes, y concibe a los ciudadanos como simples consumidores que deben residir y consumir donde puedan pagar.

Así, no es casual que, en España, bajo el concepto urbanicidio, se condenen los megaproyectos inmobiliarios que favorecieron el lucro de unos cuantos sobre la ciudad de todos. En ese país, se construyeron colosales urbanizaciones en periferias urbanas (muchas no están terminadas, ni ocupadas, ni vendidas), que arrasaron con áreas verdes, zonas agrícolas, playas y litorales. Este modelo económico, basado en la economía del ladrillo, depredó territorios, endeudó y luego desahució a cientos de miles de hogares, devastó paisajes e implicó una urbanización difusa en escala colosal, y dejó resorts sin vacacionistas, aeropuertos sin aviones y 3.4 millones de viviendas vacías, además de otros millones de casas no concluidas.

En la Ciudad de México, varios colectivos sociales usan el concepto urbanicidio para referirse a la construcción de diversos proyectos urbanos (edificios diversos, mobiliario urbano, etcétera), que lucran con la ciudad, y afectan (in)directamente a la población, encarecen las rentas y desplazan residentes y comercios de proximidad. Así, por ejemplo, desde la década de 1990 se han instalado paradas de transporte público que la ciudad "requiere", pero la empresa que dona ese mobiliario urbano recibe en concesión exclusiva la explotación comercial de los paneles informativos que integran ese mobiliario, exentos del pago de impuestos y de la energía eléctrica que usan. Aquí, los negocios creativos aparecen como filantropía.

La muerte de la ciudad también ocurre por profilaxis social, derivada de problemas sanitarios, sociales o políticos. En efecto, en la historia reciente ha habido, regímenes 
autoritarios que matan la ciudad, en términos simbólicos y materiales, para extirpar lo que consideran como un cáncer social. Rodríguez (2009) nos dice que, así como Maquiavelo afirmaba que para controlar una ciudad había que destruirla, la dictadura militar chilena en Santiago de Chile se dedicó a matar varios barrios simpatizantes del derrocado presidente Salvador Allende, dispersando a la gente a periferias distantes, bajo el discurso de combatir el déficit habitacional.

Un ejemplo diferente lo tenemos en Estados Unidos, donde a mediados del siglo XX algunos barrios eran considerados como causantes de las conductas antisociales de gente, mayoritariamente pobre, afroamericana y desempleada. En el marco de los programas de renovación urbana se demolieron barrios y grandes conjuntos habitacionales (algunos de vivienda social producidos por el Estado) para combatir lo que se consideraba un cáncer social. Byles (2005) señala que entre 1949 y 1973 el gobierno nacional destruyó 97,000 viviendas sociales en 2,500 barrios y 992 ciudades. Un ícono de estos programas de renovación urbana es la demolición del conjunto de vivienda social Pruitt Igoe en San Luis Missouri, de 33 edificios y con menos de 30 años de vida, que fue producido bajo los preceptos del urbanismo funcionalista. Aquí, la renovación urbana tenía una dimensión social, sanitaria, económica y moral.

\section{Colofón}

La muerte simbólica y material de la ciudad no es nueva. En la historia de la planificación urbana han surgido diversas visiones que intentaron construir asentamientos humanos "ordenados", pero no ciudades. Los desurbanistas soviéticos y el arquitecto estadounidense Frank Lloyd Wrigth con su proyecto Broadacre City, cada uno a su manera, pretendieron diluir las ciudades en continuos urbanos dispersos en los territorios. Durante la II Guerra Mundial como ahora frente a la pandemia COVID 19, los enemigos de la ciudad defienden esa dispersión de la ciudad y la gente en el territorio para reducir los efectos de las bombas y del coronavirus. Por su parte, Le Corbusier y los Congresos Internacionales de Arquitectura Moderna eran enemigos de la mezcla y diversidad funcional y social de la ciudad, y promovían la separación de las funciones urbanas. Bajo estos preceptos entre las décadas de 1940 y 1970 se reconstruyeron y renovaron muchas no ciudades en el mundo.

La muerte material de la ciudad (así sea parcial) y la pérdida de sus atributos han dejado de ser amenazas: la escala y velocidad del saqueo a la naturaleza que produce el capitalismo neoliberal en el planeta no tiene precedentes y provoca severos daños, como el coronavirus y el cambio climático, cuyos efectos devastan ciudades con huracanes y lluvias torrenciales. A ello se suma el descongelamiento de los polos y el elevamiento del nivel de los mares, que amenaza muchas ciudades ubicadas en litorales diversos. En todos estos casos, quienes más padecen estos desastres son los menos afortunados económicamente hablando.

Por otra parte, asistimos a una época de producción urbana insular en escala planetaria, que produce barrios dormitorio homogéneos en periferias distantes; islas seguras, exclusivas, excluyentes y homogéneas en versiones horizontales y verticales, centrales o periféricas; $y$ centros históricos parquetematizados. Asimismo, este urbanismo confina a la población de bajos ingresos a sitios que pueden pagar: quienes tienen capacidad de endeudamiento son expulsados a viviendas de pésima calidad en periferias urbanas distantes, mientras los más pobres son condenados a hacinarse en asentamientos irregulares y precarios. Así, una enorme cantidad de habitantes ha sido privada de la ciudad.

Foucault (2009) nos enseñó que el control de la población indeseable en las ciudades (por apestados, leprosos o sus ideas políticas) se hacía a través del confinamiento intraurbano o la exclusión ex-urbana, control que el panóptico perfeccionó. Sin embargo, en el siglo XXI el invento de Bentham parece rupestre frente a los modernos dispositivos de seguridad y control digital (videovigilancia, drones, policías, apps), que han optimizado el control de la gente, sobre todo en una época en que las protestas y resistencias sociales se multiplican en muchas ciudades. 
En efecto, en un mundo y en un momento en el que se urbaniza sin construir ciudad, en muchos sitios del planeta, bajo el lema del Derecho a la Ciudad, se reivindican al menos tres cosas: que la ciudad es diversidad socioeconómica y cultural, y mezcla de gente distinta, actividades y usos del suelo; que la gente viva donde quiera en una ciudad o fuera de ella, pero con servicios y equipamientos urbanos; y participar en la toma de decisiones sobre el presente y el futuro del barrio y la ciudad. Para Settis (2019), el Derecho a la Ciudad tiene también un fundamento antropológico, pues la gente construye ciudades porque busca una seguridad colectiva basada en relaciones entre iguales, en la cooperación y el intercambio franco y diverso, en un espacio común que permite ver y ser visto, el aislamiento y el encuentro, así como las actividades lúdicas y las emociones.

Las ciudades están hechas de sueños y pesadillas, de aspiraciones, recuerdos, memorias, historias, planes y leyendas, de destrucción y conservación. Una ciudad es sobre todo continuidad cultural, con cambios y transformaciones, a veces rupturistas, abruptas o paulatinas. Así, a pesar de tantos embates, la ciudad no se ha exterminado.

Indagar y reflexionar sobre la muerte (in)material de la ciudad no se deriva (sólo) del culto a las ruinas, que tienen un profundo encanto y poder de evocación sobre el pasado y el futuro de los pueblos. Varios colegas, defensores del patrimonio edificado, sostenemos que si entendemos las causas que conducen a su destrucción, tal vez estaremos mejor preparados para preservar este patrimonio, nuestra más preciada herencia colectiva en beneficio colectivo: la ciudad.

\section{Referencias bibliográficas}

Agulles, J. (2017). La destrucción de la ciudad. el mundo urbano en la culminación de los tiempos modernos. Madrid: Catarata.

Alatriste, G. (productor) \& Buñuel, L. (director) (1962). El Ángel Exterminador [cinta cinematográfica]. México: Alatriste Producciones.

Augé, M. (2008). El tiempo en ruinas. Barcelona: Gedisa.

Berman, M. (1993). Tudo sólido desmancha no ar. Sao Paulo: Companhia das Letras.

Bevan, R. (2006). The Destruction of Memory. Arquitecture at War. Londres: Reaktion Books.

Bookchin, M. (1974). Los límites de la ciudad. Madrid: Blume.

Borja, J. (2011). Revolución urbana y derecho a la ciudad. Quito: OLACCHI - Municipio Metropolitano de Quito.

Borja, J. (2003). La ciudad conquistada. Madrid: Alianza.

Bonnet, A. (2016). Fuera del mapa. Barcelona: Blackiebooks.

Brossat, I. (2019). Airbnb, la ciudad uberizada. Pamplona: Katarak.

Byles, J. (2005). Rubble. The unearthing History of Demolition. New York: Harmony Books.

Capel, H. (2003), Los problemas de las ciudades: urbs, civitas y polis. Mediterráneo Económico No. 3, 9-22.

Carrión, F. (2018a). Urbicidio o la muerte litúrgica de la ciudad. Oculum Ensaios, 15(1), 5-12.

Carrión, F. (2018b). Urbicidio o la producción del olvido. Observatorio Cultural No. 19, 28-42.

Carrión, F. (2008). Violencia urbana: un asunto de ciudad. EURE Vol. 34(103), 111-130.

Consejo Nocturno (2018). Un habitar más fuerte que la metrópoli. Logroño: Pepitas de Calabaza.

Coward, M. (2009). Urbicide. The politics of urban destruction. New York: Routledge. 
Choay, F. (2009). El reino de lo urbano y la muerte de la ciudad. Andamios 6(12), 157187.

Chueca Goitia, F. (1977). La destrucción del legado urbanístico español. Madrid: Espasa Calpe.

Delgadillo, V. (2016). Patrimonio Urbano de la Ciudad de México. La herencia disputada. México: UACM.

Fondazioni Triennal di Milano (2018), Riconstruzioni. Architettura, cittá, paessagio nell'a época della distruzioni, Milán: Silvana Editoriale.

Foucault, F. (2009). Vigilar y castigar, el nacimiento de la prisión. México: Siglo XXI.

Gamboni, D. (2014). La destrucción del arte. Iconoclasia y vandalismo desde la Revolución Francesa. Madrid: Cátedra.

Jacobs, J. (1967). Muerte y vida de las grandes ciudades. Barcelona: Península.

Jouannais, J. (2017). El uso de las ruinas. Retratos obsidionales. Barcelona: Acantilado.

Körner, M. (Editor) (1999). Stadtzerstörung und Wiederaufbau. Zerstörung durch Erdbeben, Feuer und Wasser, Band 1. Bern - Stuttgart - Wien: Verlag Paul Haupt.

Körner, M. (Editor) (2000). Stadtzerstörung und Wiederaufbau, Zerstörung durch die Stadtherrschaft, innere Unruhen und Kriege, Band 2. Bern - Stuttgart - Wien: Verlag Paul Haupt.

Lefebvre, H. (2013). La producción del espacio. Madrid: Capitán Swing.

Lynch, K. (2005). Echar a perder, análisis del deterioro. Barcelona: Gustavo Gili.

Memoria Chilena (2020). Urbanicidio. Entrada de la Biblioteca Nacional Digital, Recuperado de: http://www.memoriachilena.gob.cl/602/w3-article-95186.html.

Mongin, O. (2006). La condición urbana, la ciudad a la hora de la mundialización. Buenos Aires: PAIDOS.

Park, R. E. (1999). La Ciudad y otros ensayos de ecología urbana. Barcelona: Ediciones del Serbal.

Remy, J. (2012). "Gran ciudad y pequeña ciudad: tensiones entre sociabilidad y estética en Simmel". En F. Márquez (Editora), Ciudades de Georg Simmel, lecturas contemporáneas (pp.21-54). Santiago: Universidad Alberto Hurtado.

Rodríguez, A. y P. Rodríguez (Eds.). (2009). Santiago, una ciudad neoliberal. Quito: OLACCHI.

Sebald, W.G. (2003). Sobre la historia natural de la destrucción. Barcelona: Anagrama.

Settis, S. (2019), Wenn Venedig stirbt. Streitschrift gegen den Ausverkauf der Städte, Berlin: Wagenbach.

Spengler, 0. (2011) [1923]. La decadencia de occidente. Madrid: Espasa. [referencia no está citada en el documento como tal, solamente está mencionada]

Stovel, H. (2003). Preparación ante el riesgo: manual para el manejo del Patrimonio Cultural Mundial. República Dominicana: ICCROM - UNESCO - WHC - ICOMOS.

Topalov, Ch., L. Coudroy, J. Depaule y B. Marin (2010). L'Aventure des motes de la Ville a travers le temps, les langues, les societies. París: Editions Robert Laffont.

Wikipedia (2020), “Urbicidio”. En Wikipedia, la enciclopedia libre, accesible en: https:// es.wikipedia.org/wiki/Urbicidio.

Wirth, L. (1988). El urbanismo como modo de vida. En M. Bassols, A. Massolo y A. Méndez (Comps.), Antología de Sociología Urbana (pp.162-182). México: UNAM. 